\title{
Expression of Antibiotic Resistance Genes from Escherichia coli in Bacillus subtilis
}

\author{
Jürgen Kreft, Klaus J. Burger, and Werner Goebel \\ Institut für Genetik und Mikrobiologie der Universität Würzburg, Röntgenring 11, D-8700 Würzburg, Federal Republic of Germany
}

\begin{abstract}
Summary. Bifunctional recombinant plasmids were constructed, comprised of the $E$. coli vectors pBR322, pBR325 and $\mathrm{pACYC184}$ and different plasmids from Gram-positive bacteria, e.g. pBSU161-1 of B. subtilis and pUB110 and pC221 of $S$. aureus. The beta-lactamase (bla) gene and the chloramphenicol acetyltransferase (cat) gene from the $E$. coli plasmids were not transcribed and therefore not expressed in $B$. subtilis. However, tetracycline resistance from the $E$. coli plasmids was expressed in $B$. subtilis. Transcription of the tetracycline resistance gene(s) started in $B$. subtilis at or near the original $E$. coli promoter, the sequence of which is almost identical with the sequence recognized by $\sigma^{55}$ of $B$. subtilis RNA polymerase.
\end{abstract}

\section{Introduction}

The Gram-positive soil bacterium Bacillus subtilis is considered harmless for man and animals and is widely used in basic and applied microbiology. Efforts have been made to apply the techniques of molecular cloning, which are highly developed for the Gram-negative enterobacterium Escherichia coli, to B. subtilis (Ehrlich 1978; Goebel et al. 1979; Lovett and Keggins 1979; Dubnau et al. 1980) and several plasmid vector systems have been reported. These involve plasmids capable of replication in $B$. subtilis alone or in B. subtilis and other Gram-positive microorganisms (Ehrlich 1977; Gryczan et al. 1978; Wilson and Baldwin 1978; Bernhard et al. 1978; Gryczan and Dubnau 1978; Ehrlich et al. 1982) or alternatively bifunctional plasmids able to replicate in both $E$. coli and B. subtilis (Ehrlich 1978; Kreft et al. 1978; Kreft and Hughes 1982). In this paper we describe the construction of bifunctional plasmids which allow studies on the expression in B. subtilis of three antibiotic resistance genes from $E$. coli.

\section{Materials and Methods}

Bacterial Strains. E. coli $5 \mathrm{~K}, \mathrm{r}^{-}, \mathrm{m}^{-}$was obtained from

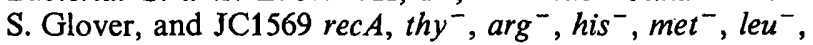
$\mathrm{Sm}^{r}$ harbouring pACYC184 from S. Cohen. B. subtilis BR151CM1 trpC2, metB10, lys3, spoCM1 was kindly provided by $P$. Lovett.

Offprint requests to: J. Kreft
Source of Reagents. All reagents if not otherwise stated were obtained from Merck, FRG. The antibiotics used were a gift from Bayer, FRG. Sodium dodecyl sulfate (SDS), ethidium bromide, polyethylene glycol type 6000 , lysozyme and pancreatic RNase were purchased from Serva, FRG.

Enzymes. The restriction enzymes EcoRI, BamHI, HindIII, SalI, PstI, XbaI and T4 DNA ligase were obtained from BRL (USA) or Biolabs (USA). S1 nuclease was purchased from BRL.

Growth of Strains, Cell Lysis and Purification of Plasmid $D N A$ were performed as previously described (Mayer et al. 1977; Bernhard et al. 1978).

Cleavage of DNA and Electrophoresis in Agarose Gels. Digestion with restriction enzymes were carried out as indicated by the manufacturers. The reactions were stopped by heating the reaction mixture to $68^{\circ} \mathrm{C}$ for $8 \mathrm{~min}$ or by addition of EDTA (100 mM final conc.). Electrophoresis was carried out in $1 \%$ agarose slab gels in $36 \mathrm{mM}$ Tris- $\mathrm{HCl}$, $30 \mathrm{mM} \mathrm{NaH}{ }_{2} \mathrm{PO}_{4}, 10 \mathrm{mM}$ EDTA, pH 7.5 (Meyers et al. 1975).

Construction of Hybrid Plasmids and Transformation. The in vitro construction of hybrid plasmids (Cohen et al. 1973) using T4.DNA ligase, transformation of $E$. coli and of B. subtilis protoplasts have been described (Goebel and Bonewald 1975; Kreft et al. 1978; Chang and Cohen 1979).

Purification of $R N A$. Isolation of RNA from $B$. subtilis BR151 was performed according to Glisin et al. (1974) by cell lysis with sarkosyl $(4 \% \mathrm{w} / \mathrm{v})$ and subsequent centrifugation through a cushion of $\mathrm{CsCl}(\rho=1.71 \mathrm{~g} / \mathrm{cm})$ in $0.1 \mathrm{M}$ EDTA pH 8.0. The RNA from the pellet was treated with DNAseI (Worthington) in the presence of ribonuclease inhibitor (vanadyl-ribonucleoside complex, BRL) to remove traces of contaminating DNA.

DNA/RNA Hybridization. The dot-blot method was used according to Kafatos et al. (1979) using 25-100 $\mu \mathrm{g}$ of RNA per dot and gene specific DNA probes labeled by nicktranslation $\left(0.5-1.0 \times 10^{6} \mathrm{cpm} / \mu \mathrm{g}\right)$ with $\alpha-{ }^{32} \mathrm{P}-\mathrm{dNTPs}$ according to de la Cruz et al. (1980).

S1 Nuclease Mapping. Transcripts were analyzed by the method of Berk and Sharp (1977). The experiments were 

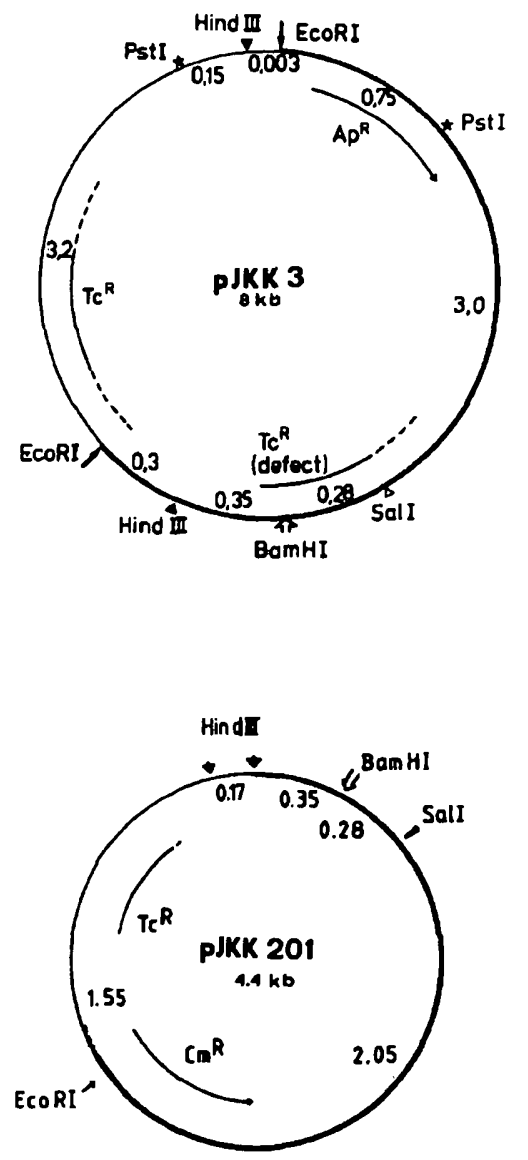

Fig. 1. Restriction maps of pJKK3 and pJKK201 for BamHI, EcoRI, HindIII, SalI and PstI. pJKK3 was constructed by ligating HindIII linearized pBR322 and PBSU161-1 (Kreft et al. 1978). The construction of pJKK201 is described in the text. Fragment sizes are given in kilobase-pairs $(\mathrm{kb})$

performed with total RNA from $B$. subtilis BR151 carrying the plasmid under study. The RNA was purified as described above. After ethanol precipitation the RNA was dissolved in $30 \mu$ l hybridization buffer (Berk and Sharp 1977) to a concentration of $6.6 \mathrm{mg} / \mathrm{ml}$. Fifteen $\mu$ of RNA $(100 \mu \mathrm{g})$ were mixed with $5 \mu \mathrm{l}$ of ${ }^{32} \mathrm{P}$-end-labeled DNA fragment $\left(0.5 \mu \mathrm{g}\right.$ DNA, $\left.5 \times 10^{5} \mathrm{cpm} / \mu \mathrm{g}\right)$. After $15 \mathrm{~min}$ at $70^{\circ} \mathrm{C}$ hybridization was carried out at $53^{\circ} \mathrm{C}$ for $4 \mathrm{~h}$. The mixture was then cooled in ice, diluted 10-fold with $\mathrm{S1}$ nuclease buffer and 37.5 units of S1 nuclease (BRL) were added. After $30 \mathrm{~min}$ at $37^{\circ} \mathrm{C}$ the hybrids were precipitated by ethanol and either applied directly to DNA sequencing gels (6\% polyacrylamide, $31 \%$ urea) or denatured in alkali (Green and Roeder 1980) prior to electrophoresis.

Elution of DNA Fragments. Restriction fragments of plasmid DNA were eluted from agarose gels by electroelution in dialysis bags using $10 \mathrm{mM}$ Tris-acetate buffer $\mathrm{pH} 8.0$ in the elution chamber $(4 \mathrm{~mA} / \mathrm{cm}, 45 \mathrm{~min})$.

DNA Sequencing. Restriction fragments from plasmid DNA were cloned into M13mp8 according to Messing and Vieira (1982). Single-stranded recombinant DNA was isolated from phage and the nucleotide sequence of the inserted DNA was determined by the chain-termination method (Sanger et al. 1977) using a synthetic oligonucleotide as primer (gift of P.H. Seeburg, Genentech).

\section{Results \\ Expression of Ampicillin Resistance}

As previously reported, hybrid plasmids consisting of the E. coli vector pBR322 (Bolivar et al. 1977) and different parts of the B. subtilis plasmid pBSU161 have been constructed in vitro (Kreft et al. 1978). Plasmid pJKK3 (Fig. 1), one of several which replicate in E. coli and $B$. subtilis, determines resistance to tetracycline and ampicillin in $E$. coli. However, ampicillin resistance was not expressed when this plasmid was transformed into $B$. subtilis. No beta-lactamase activity could be detected intracellularly. A comparison of the proteins synthesized in minicells of $E$. coli and $B$. subtilis carrying pJKK 3 or a derivative of this plasmid, where the beta-lactamase gene has been deleted in vitro, revealed that beta-lactamase and its precursor form were only synthesized in E. coli, and not in B. subtilis (Kreft et al. 1982). In order to localize the block in the expression of the beta-lactamase (bla) gene in $B$. subtilis we investigated next the in vivo transcription of this gene in $B$. subtilis. For this, RNA was purified from $B$. subtilis BR151 containing pJKK3 and dot blot hybridization (Kafatos et al. 1979) was carried out using the ${ }^{32}$ P-labeled small EcoRI/PstI fragment of pBR322, which contains most of the bla gene, as a gene specific probe. Figure 2 shows that no hybridization was obtained, indicating that the bla gene originating from pBR322 is not transcribed in B. subtilis. Deletions which may occur in pJKK3 during or subsequent to transformation into $B$. subtilis were not responsible for the lack of expression of the bla gene since this gene was fully functional upon retransformation of $E$. coli with plasmid DNA isolated from $B$. subtilis.

\section{Expression of Chloramphenicol Resistance}

A recombinant plasmid constructed in vitro from the $E$. coli vector pACYC184 (Chang and Cohen 1978) and pBSU161-1 (Kreft et al. 1978), lead in E. coli to the formation of pJKK201 (Fig. 1). The plasmid was apparently generated in vivo by an extensive deletion of the primary ligation product and expressed tetracycline and chloramphenicol resistance in $E$. coli (Kreft et al. 1978, 1982). B. subtilis could be transformed with pJKK201 to tetracycline resistance but not to chloramphenicol resistance. Plasmid DNA isolated from B. subtilis BR151 transformed with pJKK201 could retransform $E$. coli to chloramphenicol resistance. This indicates that the gene for chloramphenicol acetyltransferase (cat) is maintained in B. subtilis without rendering these cells resistant to chloramphenicol. Restriction analysis of the plasmid DNA isolated from $B$. subtilis transformed with pJKK201 also showed that the cat gene was structurally intact even in derivatives of pJKK201 which have been deleted in vivo in $B$. subtilis (results not shown).

RNA was isolated from $B$. subtilis BR151 containing pJKK201 and dot blot hybridization was carried out using the ${ }^{32}$ P-labeled small HindIII/PstI fragment of pBR325 (Bolivar 1978) as a probe-specific for $T n 9$-related cat genes. Figure 2 shows that no hybridization was obtained. This demonstrates that the cat gene from pACYC184 was also not transcribed in $B$. subtilis. 


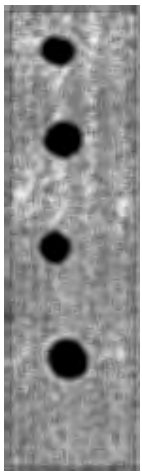

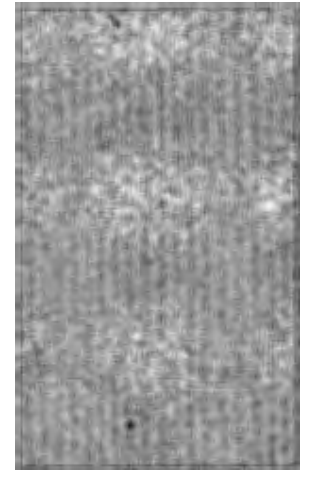

Fig. 2. Dot blot hybridization of RNA from $B$. subtilis carrying pJKK3 (b) or pJKK201 (c) with gene specific DNA probes. (a) control with pBSU161-1 DNA as a probe. From top to bottom $25,50,75$ and $100 \mu \mathrm{g}$ of RNA were applied to the filters

\section{Expression of Tetracycline Resistance}

It has been previously shown that the tetracycline resistance encoded by the Bacillus plasmid pBSU161-1 was expressed in $E$. coli (Kreft et al. 1978). We have also shown that a bifunctional plasmid consisting of the cryptic B. subtilis plasmid pBSU1 (Bernhard et al. 1978) and the $E$. coli vector pBR322 (Bolivar et al. 1977) could transform B. subtilis to tetracycline resistance (Goebel et al. 1979). In order to investigate further the expression of this $E$. coli derived tetracycline resistance determinant in $B$. subtilis two other recombinant plasmids were constructed in vitro.

pJKK310 consists of pBR325 (Bolivar 1978) and pUB110 (Gryczan et al. 1978) linearized by EcoRI and ligated subsequently with T4 DNA ligase (Fig. 3). This plasmid expressed resistance to ampicillin, kanaycin and tetracycline in $E$. coli. pJKK 523 was constructed by ligating EcoRI linearized pBR322 with the staphyloccocal chloramphenicol resistance plasmid pC221 (Ehrlich 1977) which was also linearized by EcoRI (Fig. 3). After transformation of $E$. coli with the ligation mixture, colonies were selected which were resistant to ampicillin, chloramphenicol and tetracycline. B. subtilis protoplasts could be transformed by pJKK 310 to kanamycin resistance or tetracycline resistance using DM3 regeneration plates (Chang and Cohen 1979) containing $100 \mu \mathrm{g} / \mathrm{ml} \mathrm{kanamycin} \mathrm{or} 15 \mu \mathrm{g} / \mathrm{ml}$ tetracycline, respectively. pJKK 523 could transform $B$. subtilis to chloramphenicol resistance or tetracycline resistance using $7.5 \mu \mathrm{g} / \mathrm{ml}$ chloramphenicol or $15 \mu \mathrm{g} / \mathrm{ml}$ tetracycline in the selective regeneration medium. Most of the transformants obtained on single-selective agar plates did not express the second resistance marker present on the parental plasmid isolated from $E$. coli. Attempts to obtain transformants with these plasmids on double-selective regeneration plates failed. All of the single-resistant transformants contained plasmids which had suffered large deletions. Tetracycline resistant clones of $B$. subtilis obtained after transformation with pJKK 523 harbored a deleted plasmid which contained most of the pBR322 sequence; their chloramphenicol resistant counterparts also contained a plasmid smaller than pJKK523 (results not shown). After subcultivation of the chloramphenicol resistant transformants no plasmid DNA could be isolated from these still chloramphenicol resistant strains, suggesting that the plasmid or part of it had become integrated into the chromosome. This shows that both
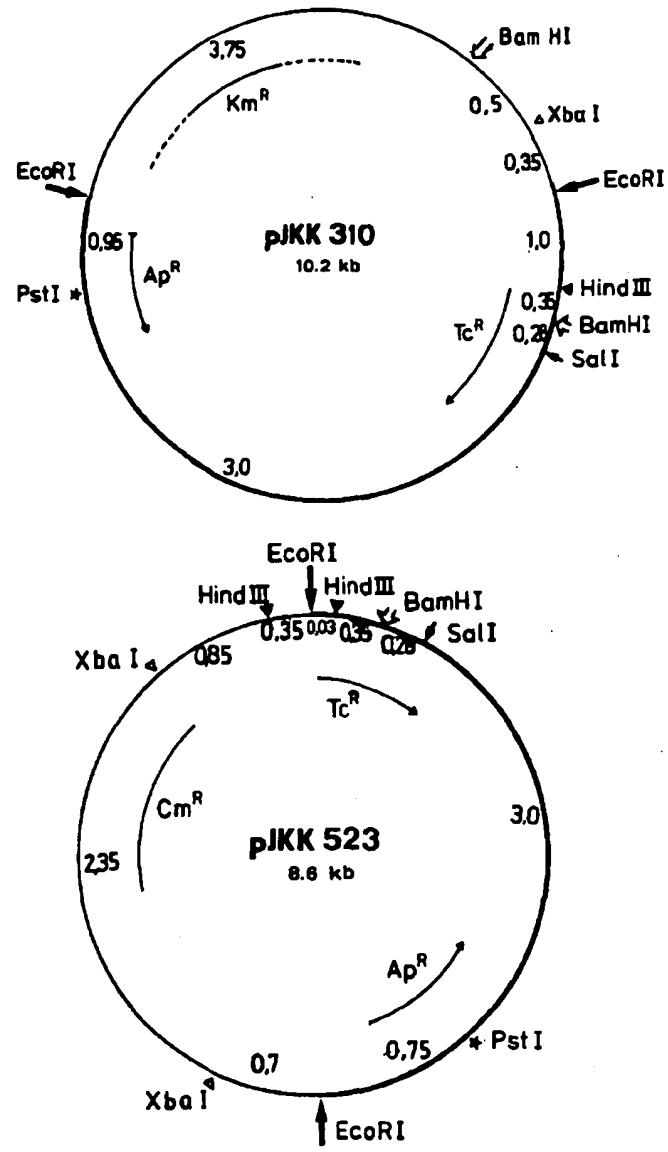

Fig. 3. Restriction maps of pJKK310 and pJKK523 for BamHI, EcoRI, HindIII, SaII, PstI and XbaI. The construction of the plasmids is described in the text. Fragment sizes are given in $\mathbf{k b}$

pJKK310 and pJKK523 are structurally unstable in $B$. subtilis.

Only a few percent of the transformants obtained with these plasmids expressed both resistance markers, i.e. kanamycin plus tetracycline resistance or chloramphenicol plus tetracycline resistance in $B$. subtilis. All these transformants contained plasmid DNA which was indistinguishable from the parental plasmids by restriction analysis (data not shown).

These results indicate that the tetracycline resistance gene (tet) of pBR322 or pBR325 was expressed in $B$. subtilis in contrast to the two other antibiotic resistance genes mentioned above.

Next; we determined if the transcription of this tet gene starts in $B$. subtilis at its original (E. coli) promoter in these hybrid replicons or whether transcription of the tetracycline resistance gene is mediated by a read-through transcript starting at a promoter in the $S$. aureus part of the recombinant plasmids. In pJKK 310 the tet gene is about $1,000 \mathrm{bp}$ away from the junction site between the two parental plasmids; in pJKK 523 this distance is only $30 \mathrm{bp}$.

By S1 nuclease mapping (Berk and Sharp 1977) we analyzed the transcripts from the $E$. coli tet gene which were synthesized in $B$. subtilis BR151 carrying intact pJKK 310 or pJKK523, respectively. Total RNA was isolated from these strains and hybridized to suitable restriction fragments of the plasmids which were end-labeled with ${ }^{32} \mathrm{P}$. In the case of pJKK310 the plasmid was cut by BamHI, labeled with ${ }^{32} \mathrm{P}-\gamma$-ATP and T4 polynucleotide kinase and 


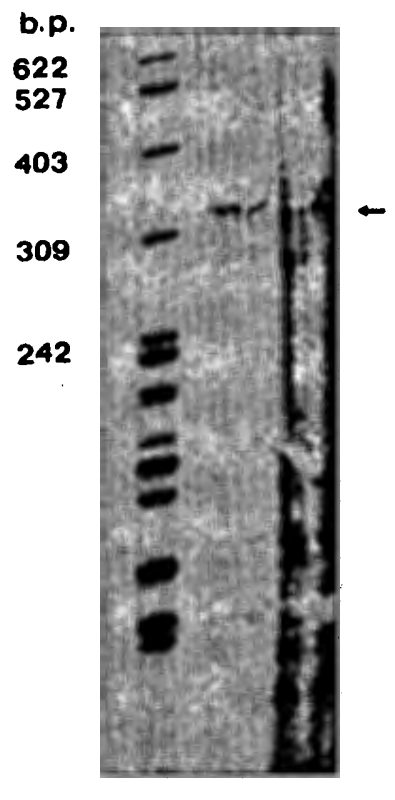

a b c

Fig. 4. S1 nuclease mapping of the $5^{\prime}$ termini of in vivo synthesized tet-gene mRNA. (a) HpaII digest of pBR322, end-labeled with ${ }^{32} \mathrm{P}$ $y$-ATP. The size in base pairs (bp) of the largest fragments is indicated on the left. (b) and (c) RNA/DNA hybrids obtained after S1 nuclease treatment of fragments of pJKK310 (b) or pJK523 (c) hybridized with in vivo synthesized RNA from $B$. subtilis containing pJKK 310 or pJKK523, respectively. The arrow indicates the largest transcript found, the smaller bands presumably represent prematurely terminated or degraded transcripts

then digested with EcoRI. The fragments were separated by electrophoresis on agarose gels. The $B a m H I / E c o$ RI fragment upstream from the BamHI site in the tetracycline resistance gene was isolated from the gel and used as a hybridization probe.

The transcription from pJKK 523 was analyzed by using the $B a m \mathrm{HI} / \mathrm{X} b a \mathrm{I}$ fragment containing the presumed start site of the tet gene for the hybridization. Treatment of the DNA/RNA-hybrids with S1 nuclease and subsequent separation on denaturing polyacrylamide/urea gels showed (Fig. 4) that the longest transcript obtained in vivo with both plasmids had a size of about 330 bases. This size is very close to the expected size for a transcript starting at the original promoter of the $E$. coli tetracycline resistance determinant (tet promoter).

To obtain further evidence that the original $E$. coli tet promoter functions in $B$. subtilis, a derivative of pJKK 310 was constructed. pJKK310 was linearized with HindIII which cuts within the -10 region of the tet promoter. The sticky ends were filled in using AMV reverse transcriptase (James et al. 1982) and blunt-end ligated by TE4 DNA ligase. $E$. coli was transformed with the ligation mixture, kanamycin resistant and tetracycline sensitive transformants were selected. One of these contained a plasmid, designated pJKK310 AHind, which was identical to pJKK310 except that the HindIII site which is located in the tet promoter was destroyed by insertion of four base pairs, thus changing the distance between the -35 and -10 regions of the tet promoter. It has been previously demonstrated that slight changes in this distance strongly affect the promoter activity in E. coli (Russel and Bennett 1982). B. subtilis protoplasts could be transformed by pJKK 310 AHind to kanamycin resistance, transformation to tetracycline resistance failed. In this case all the kanamycin resistant and tetracycline sensitive transformants contained a plasmid indistinguishable from pJKK310 $\Delta$ Hind (data not shown). This clearly indicates that inactivation of the $E$. coli tet promoter also prevented the expression of the tetracycline resistance in $B$. subtilis and further suggests that the tet gene from pBR325 (which is identical to that of pBR322) was transcribed from its own promoter in $B$. subtilis. The possibility that a frame-shift caused by the four base pair insertion at the original HindIII site resulted in the formation of an altered and inactive fusion protein transcribed and translated from the $S$. aureus part of pJKK310 can be ruled out since there are several translation-stop codons in the pBR325 sequence preceeding the tet promoter (positions 12, $29,36,44,58,66$ in pBR322) in all three reading frames.

To see if any mutation(s) occured in the tet promoter region of pJKK 310 after transformation of the plasmid into $B$. subtilis this region was sequenced and compared to the published sequence of pBR325 (Prentki et al. 1981). The nucleotide sequence of the tet promoter region of pJKK 310 was found to be identical with that of pBR325 (Fig. 5).

\section{Discussion}

The three $E$. coli genes investigated in this study which express resistance to ampicillin (bla), chloramphenicol (cat) and tetracycline (tet) are well characterized. The sequence of the structural genes and their transcription control regions in E. coli was determined (Sutcliffe 1979; Alton and Vapnek 1979). In addition the promoters and the initiation points of the in vitro transcripts have been mapped (Le Grice and Matzura 1981; Russel and Bennett 1981; Stüber and Bujard 1981).

\section{TTGACA \\ TATAAT \\ $-35$ \\ $-10$

\begin{tabular}{|c|c|}
\hline $\begin{array}{l}\text { ACCGCAAGCGACAGGCCATGTIGACA GCTTATCATCGATAAGCITIAATGCG } \\
\text { TTGTTTAIIITCTAAATACAITCAAATATGTATCCGCTCATGAGACAATAAC } \\
\text { GAAAATGAGACGTTGATC GGCACGTAAGAGGTTCCAACTTTCAC CATAATGAA }\end{array}$ & 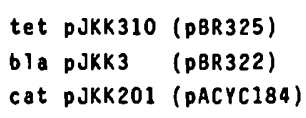 \\
\hline $\begin{array}{l}\text { TGAAAAATTTGCAAAAAGTTG TGACTTTATCTACAAGGTGTGGCATAATAAT } \\
\text { TAAAAATTTTACAAAAGGTATIGACTTTCCCTACAGGGTGTGTAATAATTTA }\end{array}$ & $\begin{array}{l}S P 01-26 \\
S P 01-15\end{array}$ \\
\hline 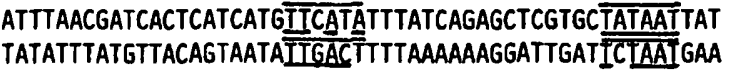 & $\begin{array}{l}\text { pE194 29k leader } \\
\text { pC194 cat }\end{array}$ \\
\hline
\end{tabular}

Fig. 5. Comparison of promoter regions. Apart from the pJKK310 tet-promoter the other sequences are derived from published information, the references are given in the text. The consensus sequences in the -35 and -10 regions of $B$. subtilis vegetative promoters are shown on top. The -35 and -10 regions of the promoters discussed here are overlined, sequences homologous to the consensus sequences are underlined, those with additional homology to SPO1 promoters are indicated by broken lines 
The transcriptional mechanism of B. subtilis is more complex than that of $E$. coli (Losick and Pero 1981). The similarity between $E$. coli promoters and $B$. subtilis vegetative promoters (Lee and Pero 1981; Losick and Pero 1981; Moran et al. 1982) may suggest that the lack of expression of $E$. coli genes in B. subtilis is not caused by differences in these sequences.

Our data presented here, however, suggest that the RNA polymerase of $B$. subtilis is apparently unable to transcribe the $E$. coli genes determining ampicillin resistance (bla) and chloramphenicol resistance (cat) on the plasmids pBR322 and pACYC184 when they are introduced into $B$. subtilis via recombinant plasmids. From these data it cannot be ruled out that mRNAs transcribed from $E$. coli genes are extremely unstable in B. subtilis. However, the successful expression of the tet gene from $E$. coli in this host indicates that this is not the case. In contrast to the $E$. coli bla and cat genes the determinant for tetracycline resistance (tet) on pBR322 and pBR325 is expressed in $B$. subtilis. In $E$. coli transcription of the tet-gene starts about 335 base pairs upstream from the BamHI site on pBR322 (West and Rodriguez 1982; J. Lowrie and J. Hedgpeth, personal communication). The longest transcript synthesized in $B$. subtilis from the corresponding part of the recombinant plasmids pJKK 310 and pJKK 523 as determined by $\mathrm{S} 1$ nuclease mapping is about 330 bases in size. This strongly suggests that the tet gene is transcribed in $B$. subtilis from its original $E$. coli promoter. From these results and those obtained with the related plasmid pJKK310A Hind, where the E. coli tet promoter has been destroyed, it can be ruled out that transcription of the tet gene starts at a promoter in the $S$. aureus part of the hybrid plasmids.

If one compares the consensus sequences in the -35 and -10 regions (TTGACA and TATAAT, respectively) of $B$. subtilis vegetative promoters (Losick and Pero 1981) which are recognized by the initiation factor $\sigma^{55}$, with the corresponding sequences of the $E$. coli bla, cat and tet promoters one observes a striking homology between the $B$. subtilis and the E. coli tet promoters with only one mismatch in the -10 region (Fig. 5). On the other hand the promoter sequence for the bla gene shows two mismatches in both the -35 and -10 regions with three purine/pyrimidine nucleotide substitutions. The cat promoter has hardly any homology in the -35 region, the sequence with maximum homology having four mismatches with three purine/ pyrimidine nucleotide substitutions; the -10 region has one mismatch, in addition the distance between the -35 and -10 regions is 20 base pairs instead of the 17 base pairs found with the other promoters (Fig. 5).

The B. subtilis phage SPO1 early genes SPO1-15 and SPO1-26 show conserved oligo-(dA) and oligo-(dT) sequences upstream from the -35 region (Lee and Pero 1981) (Fig. 5). It has been quoted that such sequences may be essential for B. subtilis vegetative promoters (Murray and Rabinowitz 1982; S. Chang, 4th International Symposium on Genetics of Industrial Microorganisms, Kyoto 1982). However, neither the $E$. coli tet promoter nor the promoters of the $29 \mathrm{k}$ leader peptide from pE194 (Horinouchi and Weisblum 1980; Gryczan et al. 1980) which initiates transcription of the erythromycin resistance gene, and of the pC194 cat gene (Horinouchi and Weisblum 1982) show such sequences (Fig. 5). Nevertheless all three genes, which only show homology in their -35 and -10 regions, are readily expressed in B. subtilis (Ehrlich 1977; Weisblum et al. 1979).

Therefore it seems likely that the degree of homology in the -35 and -10 promoter regions of heterolous genes with the consensus sequence for $B$. subtilis vegetative $\left(\sigma^{55}\right)$ promoters is essential for the expression in vegetative $B$. subtilis cells. Additional sequence homologies in other parts of the promoter region may well have an influence on the promoter efficiency in this bacterium, in which, apparently, more stringent sequence requirements have to be met by promoters than in $E$. coli.

Acknowledgements. The authors wish to thank M. Vogel for her expert technical assistance, A. Juarez for performing a large portion of the DNA sequencing, I. Grummt for advice on S1 nuclease mapping, M.S. Gilmore for reading of the manuscript and K.F. Fischbach for help during the computer editing of it. J. Lowrie and J. Hedgpeth are thanked for communicating results prior to publication.

This work was supported by a grant from the Deutsche Forschungsgemeinschaft (SFB $105-$ A11).

\section{References}

Alton NK, Vapnek D (1979) Nucleotide sequence analysis of the chloramphenicol resistance transposon $T n 9$. Nature 282:864-869

Berk AJ, Sharp PA (1977) Sizing and mapping of early adenovirus mRNAs by gel electrophoresis of $\mathrm{S} 1$ endonuclease-digested bybrids. Cell 12:721-732

Bernhard K, Schrempf H, Goebel W (1978) Bacteriocin and antibiotic resistance plasmids in Bacillus cereus and Bacillus subtilis. J Bacteriol 133:897-903

Bolivar F (1978) Construction and characterization of new cloning vehicles. III. Derivatives of plasmid pBR322 carrying unique $E c o$ RI sites for selection of EcoRI generated recombinant molecules. Gene 4:121-136

Bolivar F, Rodriguez RL, Greene PJ, Betlach MC, Heyneker HL, Boyer HW, Crosa JH, Falkow S (1977) Construction and characterization of new cloning vehicles. II. A multipurpose cloning system. Gene 2:95-113

Chang ACY, Cohen SN (1978) Construction and characterization of amplifiable multicopy DNA cloning vehicles derived from the P15A cryptic miniplasmid. J Bacteriol 134:1141-1156

Chang S, Cohen SN (1979) High frequency transformation of $B a-$ cillus subtilis protoplasts by plasmid DNA. Mol Gen Genet 168:111-115

Cohen SN, Chang ACY, Boyer HW, Helling RB (1973) Construction of biologically functional plasmids in vitro. Proc Natl Acad Sci USA 70:3240-3244

Cruz de la F, Müller D, Ortiz JM, Goebel W (1980) Hemolysis determinant common to Escherichia coli hemolytic plasmids of different incompatibility groups. J Bacteriol 143: 825-833

Dubnau D, Gryczan TJ, Contente S, Shivakumar AG (1980) Molecular cloning in Bacillus subtilis. In: Setlow JK, Hollaender A (eds) Genetic engineering. Plenum Press, New York, pp 115131

Ehrlich SD (1977) Replication and expression of plasmids from Staphylococcus aureus in Bacillus subtilis. Proc Natl Acad Sci USA $74: 1680-1682$

Ehrlich SD (1978) DNA cloning in Bacillus subtilis. Proc Natl Acad Sci USA 75:1433-1436

Ehrlich SD, Niaudet B, Michel B (1982) Use of plasmids from Staphylococcus aureus for cloning of DNA in Bacillus subtilis. Current Topics Microbiol Immunol 96:19-29

Glisin V, Crkvenjakov R, Byus C (1974) Ribonucleic acid isolation by cesium chloride centrifugation. Biochemistry 13:2633-2637

Goebel W, Bonewald R (1975) Class of small multicopy plasmids originating from the mutant antibiotic resistance factor R1drd19B2. J Bacteriol 123:658-665 
Goebel W, Kreft J, Burger KJ (1979) Molecular cloning in Bacillus subtilis. In: Timmis KN, Pühler A (eds) Plasmids of medical, environmental and commercial importance. Elsevier/NorthHolland Biomedical Press, Amsterdam, pp 471-480

Goldfarb DS, Doi RH, Rodriguez RL (1981) Expression of Tn9derived chloramphenicol resistance in Bacillus subtilis. Nature 293:309-311

Goldfarb DS, Rodriguez RL, Doi RH (1982) Translational block to expression of the Escherichia coli Tn9-derived chloramphenicol resistance gene in Bacillus subtilis. Proc Natl Acad Sci USA 79:5886-5890

Green MR, Roeder RG (1980) Definition of a novel promoter for the major adenovirus-associated virus mRNA. Cell $22: 231-242$

Gryczan TJ, Dubnau D (1978) Construction and properties of chimeric plasmids in Bacillus subtilis. Proc Natl Acad Sci USA 75:1428-1432

Gryczan TJ, Contente S, Dubnau D (1978) Characterization of Staphylococcus aureus plasmids introduced by transformation into Bacillus subtilis. J Bacteriol 134:318-329

Gryczan TJ, Grandi G, Grandi R, Dubnau D (1980) Conformational alteration of mRNA structure and the post-transcriptional regulation of erythromycin-induced drug resistance. Nucleic Acids Res 8:6081-6097

Horinouchi S, Weisblum B (1980) Post-transcriptional modification of mRNA conformation: Mechanism that regulates erythromycin-induced resistance. Proc Natl Acad Sci USA 77:7079-7083

Horinouchi S, Weisblum B (1982) Nucleotide sequence and functional map of pC194, a plasmid that specifies inducible chloramphenicol resistance. J Bacteriol 150:815-825

James AA, Morrison PT, Kolodner R (1982) Genetic recombination of bacterial plasmid DNA. Analysis of the effect of recombination-deficient mutations on plasmid recombination. $\mathrm{J}$ Mol Biol 160:411-430

Kafatos FC, Jones CW, Efstradiadis A (1979) Determination of nucleic acid sequence homologies and relative concentrations by a dot hybridization procedure. Nucleic Acids Res 7:1541-1552

Kreft J, Bernhard K, Goebel W (1978) Recombinant plasmids capable of replication in B. subtilis and E. coli. Mol Gen Genet 162:59-67

Kreft J, Hughes C (1982) Cloning vectors derived from plasmids and phage of Bacillus. Current Topics Microbiol Immunol 96:1-17

Kreft J, Parrisius J, Burger KJ, Goebel W (1982) Expression and instability of heterologous genes in B. subtilis. In: Ganesan AT, Chang S, Hoch JA (eds) Molecular cloning and gene regulation in Bacilli. Academic Press, New York, pp 145-157

Lee G, Pero J (1981) Conserved nucleotide sequences in temporally controlled bacteriophage promoters. J Mol Biol 152:247-265

Le Grice SFJ, Matzura H (1981) Binding of RNA polymerase and the catabolite gene activator protein within the cat promoter in Escherichia coli. J Mol Biol 150:185-196

Losick R, Pero J (1981) Cascades of sigma factors. Cell 25:582-584

Lovett PS, Keggins KM (1979) Bacillus subtilis as a host for molecular cloning. In: Wu R (ed) Methods in microbiology, vol 68 . Academic Press, New York, pp 342-357
Mayer H, Luibrand G, Goebel W (1977) Replication of the miniR1 plasmid Rsc11 and Rsc11 hybrid plasmids. Mol Gen Genet $152: 145-152$

Messing J, Vieira J (1982) A new pair of M13 vectors for selecting either DNA strand of double-digest restriction fragments. Gene $19: 269-276$

Meyers J, Sanchez D, Elwell L, Falkow S (1975) Simple agarose gel electrophoretic method for the identification and characterization of plasmid deoxyribonucleic acid. J Bacteriol 127:1529-1537

Moran CP Jr, Lang N, Le Grice SFJ, Lee G, Stephens M, Sonenshein AL, Pero J, Losick R (1982) Nucleotide sequences that signal the initiation of transcription and translation in Bacillus subtilis. Mol Gen Genet 186:339-346

Murray CL, Rabinowitz JC (1982) Nucleotide sequences of transcription and translation initiation regions in Bacillus phage $\phi 29$ early genes. J Biol Chem 257:1053-1062

Prentki P, Karch F, Iida S, Meyer J (1981) The plasmid cloning vector pBR325 contains a 482 base-pair-long inverted duplication. Gene 14:289-299

Russel DR, Bennett GN (1981) Characterization of the beta-lactamase promoter of pBR322. Nucl Acids Res 9:2517-2533

Russel DR, Bennett GN (1982) Construction and analysis of in vivo activity of $E$. coli promoter hybrids and promoter mutants that alter the -35 to -10 spacing. Gene $20: 231-243$

Sanger F, Nicklen S, Coulson AR (1977) DNA sequencing with chain-terminating inhibitors. Proc Natl Acad Sci USA 74:5463-5467

Stüber D, Bujard H (1981) Organization of transcriptional signals in plasmids pBR322 and pACYC184. Proc Natl Acad Sci USA $78: 167-171$

Sutcliffe JG (1979) Complete nucleotide sequence of the Escherichia coli plasmid pBR322. Cold Spring Harbor Symp Quant Biol 43:77-90

Weisblum B, Graham MY, Gryczan TJ, Dubnau A (1979) Plasmid copy number control: Isolation and characterization of highcopy number mutants of plasmid pE194. J Bacteriol 137:635-643

West RW Jr, Rodriguez RL (1982) Construction and characterization of E. coli promoter-probe plasmid vectors. II. pBR322 derivatives with deletions in the tetracycline resistance promoter region. Gene 20:291-304

Williams DM, Schoner RG, Duvall EJ, Preis LH, Lovett PS (1981) Expression of Escherichia coli trp genes and the mouse dihydrofolate reductase gene cloned in Bacillus subtilis. Gene 16:199-206

Wilson CR, Baldwin JN (1978) Characterization and construction of molecular cloning vehicles within Staphylococcus auretus. J Bacteriol 136:402-413

Communicated by E. Bautz

Received February 23, 1983 